\title{
Using a White Light Confocal Profiler for Ancient Diet Reconstruction
}

Ashley Remy ${ }^{1}$, Christopher Schmidt ${ }^{1}$, Ruggero D’Anastasio²

${ }^{1}$ University of Indianapolis, Indianapolis IN USA

${ }^{2}$ Museo Universitario Università "G. d'Annunzio", Chieti e Pescara, Italy

Dental-based dietary reconstruction is a process of examining occlusal surfaces of ancient teeth by means of Dental Microwear Texture Analysis (DMTA). Diets indicate subsistence strategies such as lifeways including either hunting and gathering, fishing, agriculture, or pastoralism. DMTA uses a White Light Confocal Profiler (WLCP) to interpret surface microtopography. In general, foragers have rougher surfaces while farmers, who processed their food more, have smoother surfaces and their microfeatures aligned in a common direction.

Herculaneum, an ancient Roman town, gives a unique opportunity to employ these methods of diet reconstruction. In AD 79, Herculaneum, along with Pompeii, was destroyed by the eruption of Mt. Vesuvius. Archaeological excavations recovered skeletal remains of approximately 300 individuals along the coast of Herculaneum [1]. The nature of these individuals' deaths allows us the rare opportunity of having a snapshot in time. The recovery of numerous subsistence artifacts and actual food items (including copious seeds and nuts) allowed us to predict that these people should have a diet that is somewhat rougher than might be expected for what is generally considered a fishing village diet. Data were collected with the WLCP and studied via scalesensitive fractal geometry software. The variables include Complexity (surface roughness), Anisotropy (similarity of feature orientation), and Textural Fill Volume (amount of surface removed) on high resolution casts of molar Phase II occlusal wear facets. Phase II facets were selected because they are the area on the tooth where food is crushed during mastication. Magnification was 100X. Data were studied with Sfrax ${ }^{\circledR}$ and Toothfrax ${ }^{\circledR}$ software, and the statistical procedures employed ANOVA.

Our results indicated that our prediction was correct, Herculaneum did consume a somewhat harder diet, with values of 1.46 for complexity and .0033 for anisotropy, although some of this hardness is biased by the children who had a harder diet than the adults. It is unclear at this point why children have greater roughness, but this has been seen in Medieval children as well. Overall, the Herculaneum diet appears to be diverse and ranges well beyond fish consumption (which usually leads to smooth tooth surfaces). Ongoing study involves interpreting the data in the context of this group of people who died simultaneously so we can better understand how diets vary within the population. 

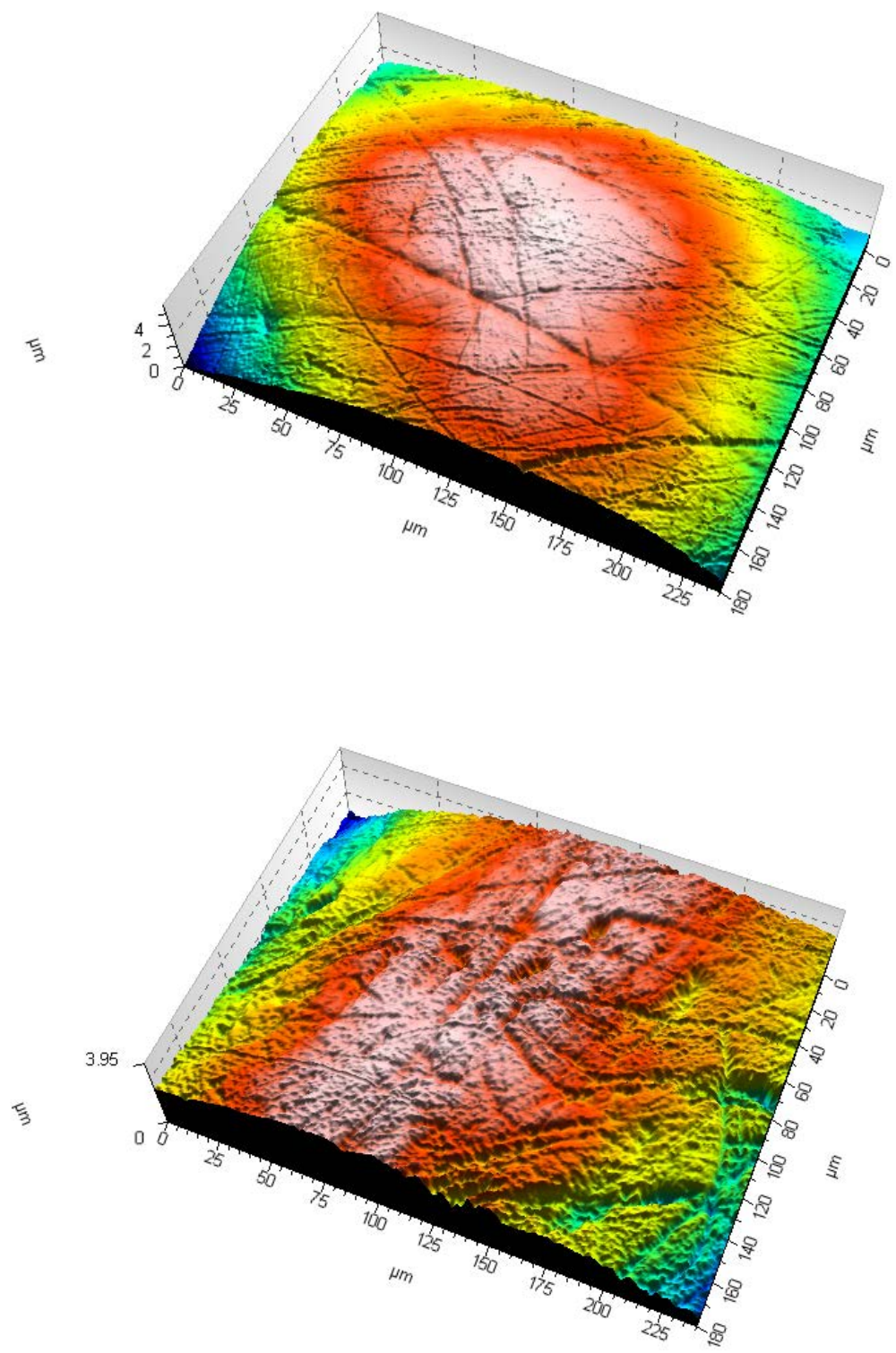

Figure 1 and 2. Examples of DMTA from the individuals of Herculaneum as seen with fractal software.

References:

[1] Capasso, L. (2001). I fuggiaschi di Ercolano: paleobiologia delle vittime dell'eruzione vesuviana del $79 \mathrm{dC}$. 